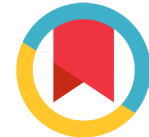

Check for updates
For correspondence:

amohamadii1361@gmail.com

Competing interests: The authors declare that no competing interests exist.

Received: 19 October 2017

Accepted: 07 November 2017

Published: 18 December 2017

Copyright The Author(s) 2017. This article is published with open access by BioMedPress

This article is distributed under the terms of the Creative Commons Attribution License (CC-BY 4.0) which permits any use, distribution, and reproduction in any medium, provided the original author(s) and the source are credited.

\section{Role of socioeconomic disparities in incidence and mortality of chronic kidney disease}

\author{
Mahdi Mohammadian1,2, Hamid Salehiniya3, Fatemeh Allah \\ Bakeshei4 , Abdollah Mohammadian-Hafshejani5,6,*
}

${ }^{1}$ Department of Social Medicine, School of Public Health, Dezful University of Medical Sciences, Dezful, Iran

${ }^{2}$ Researcher, School of Public Health, Iran University of Medical Sciences, Tehran, Iran 3Zabol University of Medical Sciences, Zabol, Iran

4PhD Candidate, Social Determinants of Health Research Center, University of Social Welfare and Rehabilitation Sciences, Tehran, Iran

5Department of Epidemiology and Biostatistics, School of Public Health, Shahrekord University of Medical Sciences, Shahrekord, Iran

6Department of Epidemiology and Biostatistics, School of Public Health, Tehran University of Medical Sciences, Tehran, Iran

\section{Keywords}

Chronic kidney disease, End-stage renal disease, Poverty, Socioeconomics

\section{Dear Editor-in-Chief}

Chronic kidney disease (CKD) is a public health problem known as one of the most important factors for premature death (Coresh et al., 2007; Martins et al., 2012). The disparity in the distribution of CKD is due to the socio-economic factors, gender, ethnicity and race at the global level (Norris and Nissenson, 2008; Norris and Agodoa, 2005). Roles of socio-economic conditions have been recently taken into account as a key factor in the pathway of CKD creation and expansion (Bruce et al., 2009; Nicholas et al., 2015). Several studies worldwide investigated a strong relationship between socioeconomic status and incidence 
of CKD complications (Crews et al., 2012; Jurkovitz et al., 2012; Saab et al., 2012). Martins et al. studied the relationship between microalbuminuria and macroalbuminuria and the individual economic and social situation in the United States of America, so that the odds ratio of microalbuminuria in the poor (defined as less than $200 \%$ federal poverty level) was equal to 1.35 ; $95 \%$ confidence interval (Cl): 1.22-1.49 and for macroalbuminuria was equal to 1.78 ; $95 \% \mathrm{Cl}: 1.40-2.26$ compared to other people. According to another study by Lipworth et al., the risk of end-stage renal disease (ESRD) in people with the income level of less than or equal to $\$ 15000$ per year was $50 \%$ more than others (Lipworth et al., 2012). Risk of ESRD incidence in homeless people was also more than those who lived in houses. According to a research by Jurkovitz et al on people aged 65 and under at the high risk of CKD (people with diabetes or hypertension, and also those with a family history of CKD), the probability of ESRD incidence in the poor without insurance was $72 \%$ higher than the poor with insurance (Jurkovitz et al., 2012). Therefore, the lack of health insurance, which is more prevalent among the poor, is, in fact, a risk factor for incidence of ESRD among people at the high risk of disease. Consequently, it is suggested paying attention to people at lower social and economic classes, homeless people and those without health insurance in case finding and screening programs. Health policy makers should also pay attention to roles of social and economic factors in the prevention of incidence and reduction of complications and mortality due to the kidney diseases. Appropriate measures should also be taken to put the poor under the health insurance coverage to reduce the incidence and mortality of kidney diseases.

\section{Abbreviations}

$\mathrm{Cl}$ : Confidence Interval

CKD: Chronic kidney disease

ESRD: End Stage Renal Disease

\section{References}

Bruce, M.A., Beech, B.M., Sims, M., Brown, T.N., Wyatt, S.B., Taylor, H.A., Williams, D.R., and Crook, E. (2009). Social environmental stressors, psychological factors, and kidney disease. Journal of investigative medicine : the official publication of the American Federation for Clinical Research 57, 583-589.

https://doi.org/10.2310/JIM.0b013e31819dbb91

Coresh, J., Selvin, E., Stevens, L.A., Manzi, J., Kusek, J.W., Eggers, P., Van Lente, F., and Levey, A.S. (2007). Prevalence of chronic kidney disease in the United States. Jama 298, 2038-2047.

https://doi.org/10.1001/jama.298.17.2038 
Crews, D.C., McClellan, W.M., Shoham, D.A., Gao, L., Warnock, D.G., Judd, S., Muntner, P., Miller, E.R., and Powe, N.R. (2012). Low income and albuminuria among REGARDS (Reasons for Geographic and Racial Differences in Stroke) study participants. American journal of kidney diseases : the official journal of the National Kidney Foundation 60, 779-786.

\section{https://doi.org/10.1053/j.ajkd.2012.05.010}

Jurkovitz, C.T., Elliott, D., Li, S., Saab, G., Bomback, A.S., Norris, K.C., Chen, S.C., McCullough, P.A., and Whaley-Connell, A.T. (2012). Physician utilization, risk-factor control, and CKD progression among participants in the Kidney Early Evaluation Program (KEEP). American journal of kidney diseases : the official journal of the National Kidney Foundation 59, S24-33.

https://doi.org/10.1053/j.ajkd.2011.11.019

Lipworth, L., Mumma, M.T., Cavanaugh, K.L., Edwards, T.L., Ikizler, T.A., Tarone, R.E., McLaughlin, J.K., and Blot, W.J. (2012). Incidence and predictors of end stage renal disease among low-income blacks and whites. PloS one 7, e48407.

\section{https://doi.org/10.1371/journal.pone.0048407}

Martins, D., Agodoa, L., and Norris, K. (2012). Kidney disease in disadvantaged populations. International journal of nephrology 2012, 469265.

https://doi.org/10.1155/2012/469265

Nicholas, S.B., Kalantar-Zadeh, K., and Norris, K.C. (2015). Socioeconomic disparities in chronic kidney disease. Advances in chronic kidney disease 22, 6-15.

https://doi.org/10.1053/j.ackd.2014.07.002

Norris, K., and Nissenson, A.R. (2008). Race, gender, and socioeconomic disparities in CKD in the United States. Journal of the American Society of Nephrology: JASN 19, 1261-1270.

\section{https://doi.org/10.1681/ASN.2008030276}

Norris, K.C., and Agodoa, L.Y. (2005). Unraveling the racial disparities associated with kidney disease. Kidney international 68, 914-924.

https://doi.org/10.1111/j.1523-1755.2005.00485.x

Saab, G., Chen, S.C., Li, S., Bomback, A.S., Whaley-Connell, A.T., Jurkovitz, C.T., Norris, K.C., and McCullough, P.A. (2012). Association of physician care with mortality in Kidney Early Evaluation Program (KEEP) participants. American journal of kidney diseases : the official journal of the National Kidney Foundation 59, S34-39.

https://doi.org/10.1053/j.ajkd.2011.11.020 